\title{
A Case of a Cutaneous Angiomyolipoma
}

\author{
Jung-u Shin, M.D., Kyu-yeoop Lee, M.D., Mi Ryung Roh, M.D. \\ Department of Dermatology and Cutaneous Biology Research Institute, Yonsei University College of Medicine, Seoul, Korea
}

\begin{abstract}
A cutaneous angiomyolipoma, which is also known as a cutaneous angiolipoleiomyoma, is a rare benign mesenchymal tumor. Only 18 cases have been reported in the English literature. We describe a case of an angiomyolipoma presenting on the right ear helix of a 26-year-old female. The histopathologic examination revealed a typical form of an angiomyolipoma with a proliferation of mature adipocytes. As with all previously reported cases, our patient did not present with the stigmata of tuberous sclerosis. This is the 20th reported case of cutaneous angiomyolipoma and the 3rd reported case in Korea. (Ann Dermatol 21(2) $217 \sim 220$, 2009)
\end{abstract}

\section{-Keywords-}

Angiolipoleiomyoma, Angiomyolipoma

\section{INTRODUCTION}

An angiomyolipoma (AML) is a tumor composed of various amounts of fat, smooth muscle, and blood vessels that usually affect the kidney as a solitary or multicentric mass. Extrarenal AMLs are extremely rare and have been reported in the liver, nasal cavity, oral cavity, heart, colon, lung, and $\operatorname{skin}^{1}$. Cutaneous $\mathrm{AML}$, also known as a cutaneous angiolipoleiomyoma, is a rare benign tumor; only 18 cases had been reported in the English literature. Histologically, AML is a circumscribed nodule consisting of a proliferation of smooth muscle bundles, blood vessels, and mature adipose tissue ${ }^{2}$. Although renal AMLs are associated with tuberous sclerosis in one-third of

Received December 14, 2007, Accepted for publication September 2, 2008

Reprint request to: Mi Ryung Roh, M.D., Department of Dermatology and Cutaneous Biology Research Institute, Yonsei University College of Medicine, 134, Shinchon-dong, Seodaemoon-gu, Seoul 120-752, Korea. Tel: 82-2-2228-2090, Fax: 82-82-2-393-9157, E-mail: karenroh @yuhs.ac, derma@yuhs.ac cases, no cases of cutaneous AMLs have been associated with tuberous sclerosis to date. We report herein a 26year-old female with a cutaneous AML on the helix of her right ear.

\section{CASE REPORT}

A 26-year-old Korean female noticed an asymptomatic, solitary, pea-sized, blue subcutaneous nodule on the helix of the right ear for several years (Fig. 1). The physical examination revealed a blue, non-tender nodule covered with normal skin. She was otherwise in good health and had no clinical signs of the tuberous sclerosis complex (TBC), including hypopigmented macules, facial angiofibromas, shagreen patches, or renal AML. There was no family history and the features of tuberous sclerosis were not identified. Under the clinical impression of a mucoid cyst, we performed a punch excision on the nodule. The nodule was completely excised after the biopsy without any complications. There was no recurrence during the 3

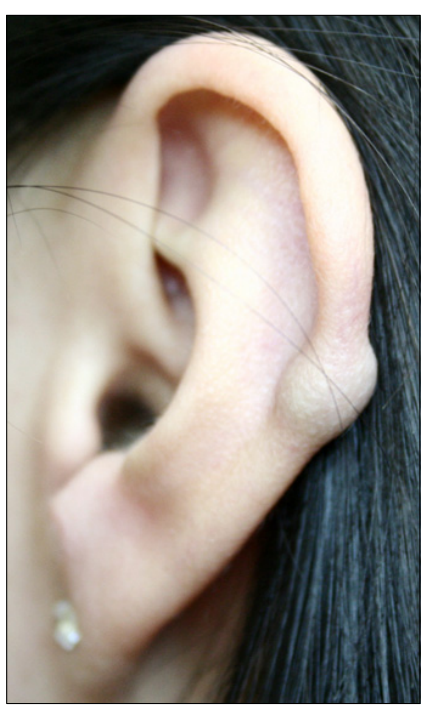

Fig. 1. Pea-sized blue nodule on the helix of the left ear. 

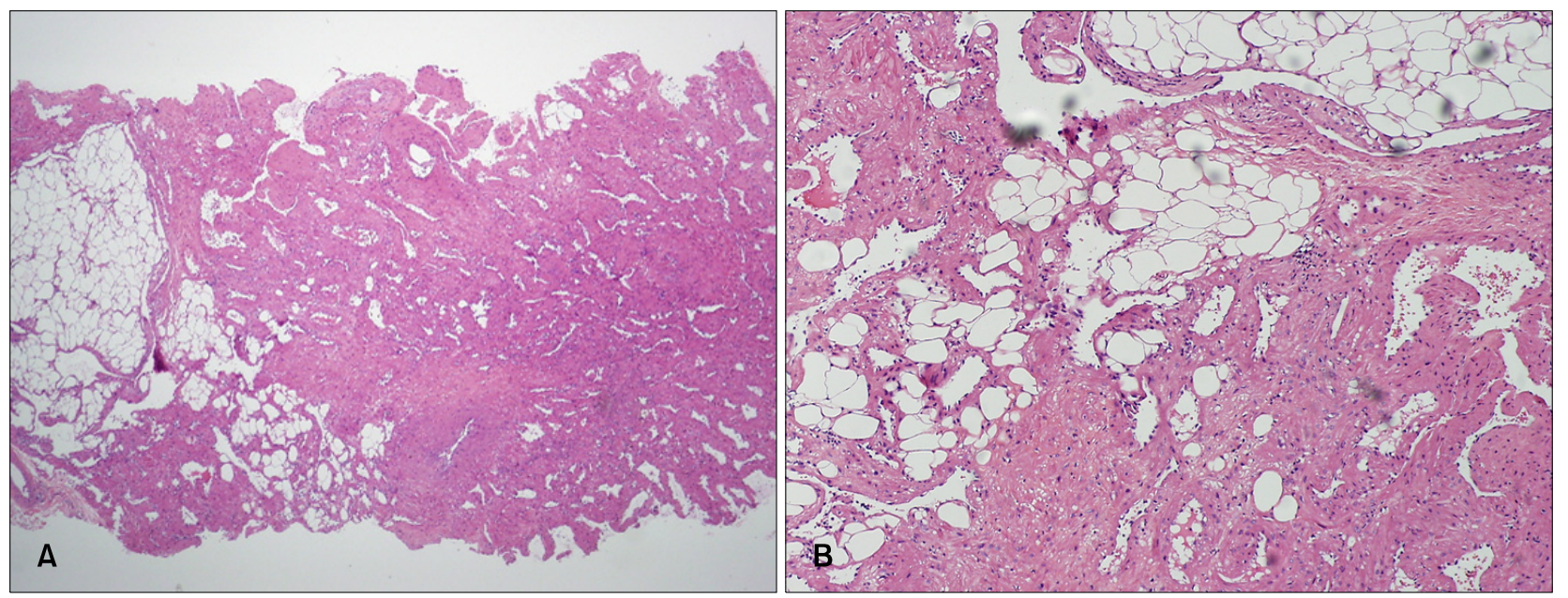

Fig. 2. Hematoxylin-eosin-stained section shows variable-sized blood vessels, smooth muscle bundles, and mature adipose tissue (A: $\times 40$, B: $\times 100$ ).

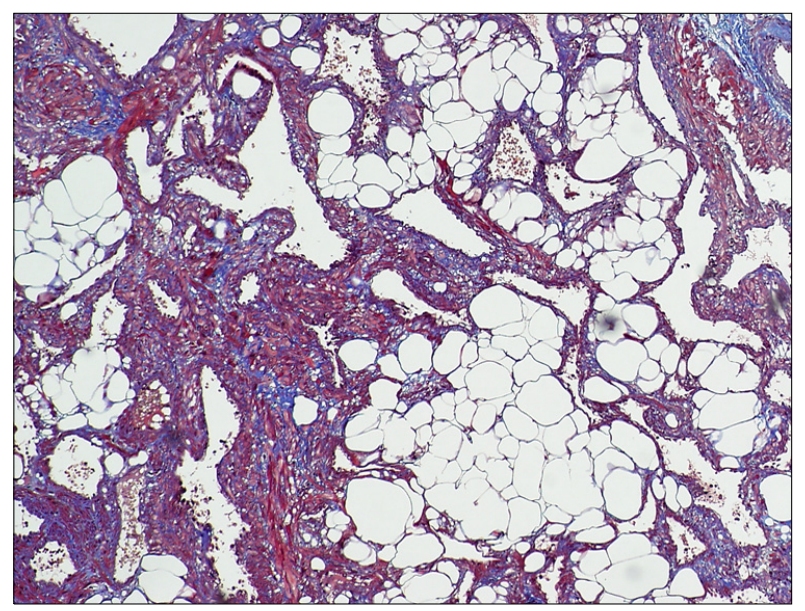

Fig. 3. Masson trichrome stained the muscular portions of the tumors bright red and the collagen blue $(\times 100)$.

month follow-up period.

On hematoxylin-eosin-stained sections of the tumor, vascular spaces, smooth-muscle bundles, and mature adipose tissue were identified. The three components had proliferated in variable quantities. The blood vessels were mostly small-to-medium in size and had thick muscular walls, in part, continuously intermingled with the surrounding smooth muscle bundles. Cellular pleomorphism and mitotic figures were absent (Fig. 2). Masson trichrome staining stained the muscular portions of the tumors bright red and the collagen blue (Fig. 3). Verhoef van Giesonstained small arterioles were noted within the lesions (Fig. 4). Immunohistochemical analysis showed no reactivity for HMB-45 antibody as in other case reports ${ }^{3,4}$. Based on these histologic and immunohistochemical features, a diagnosis of

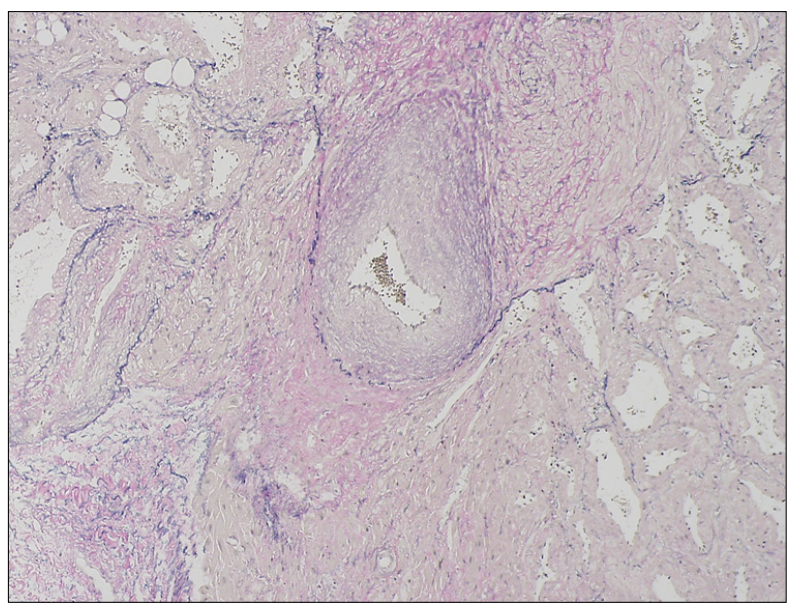

Fig. 4. Elastica van Gieson staining stained small arterioles within the lesions $(\times 100)$.

cutaneous AML was made.

\section{DISCUSSION}

AMLs, previously termed cutaneous angiolipoleiomyomas, most commonly arise in the kidney, but have also been described in a large number of the body (liver, nasal cavity, oral cavity, heart, colon, lung, and skin) ${ }^{1}$. Fitzpatrick et $\mathrm{al}^{5}$ provided the first report of a cutaneous AML, under the name cutaneous angiolipoleiomyoma, in 1990. Argenyi et $\mathrm{al}^{2}$ reported an additional case, occurring on the upper helix of the ear 1 year later. Since then, 9 additional cases have been reported, bringing the total cited in the English literature to $18^{6-12}$. The clinical features of the 21 published cases, including the case 
Table 1. Clinical features of the 21 cutaneous angiomyolipoma cases

\begin{tabular}{|c|c|c|c|c|c|c|c|c|c|}
\hline $\begin{array}{c}\text { Case } \\
\text { no. }\end{array}$ & Study & Age & Sex & Size & Location & $\begin{array}{l}\text { Dura- } \\
\text { tion }\end{array}$ & $\begin{array}{l}\text { Recur- } \\
\text { rence }\end{array}$ & Preoperative differential & Unusual findings \\
\hline 1 & Fitzpatrick et al (1990) & 77 & $M$ & - & - & - & - & Mucoid cyst & - \\
\hline 2 & Fitzpatrick et al (1990) & 63 & $M$ & - & - & $6 \mathrm{mo}$ & - & Unspecified mass & - \\
\hline 3 & Fitzpatrick et al (1990) & 50 & $M$ & - & Head & - & - & Nodule & - \\
\hline 4 & Fitzpatrick et al (1990) & 59 & $\mathrm{~F}$ & - & Elbow & - & - & Lipoma, cyst & - \\
\hline 5 & Fitzpatrick et al (1990) & 52 & $M$ & - & Hand & $1 \mathrm{y}$ & - & Epidermal cyst & - \\
\hline 6 & Fitzpatrick et al (1990) & 33 & $M$ & - & Toe & $3 y$ & - & Lipoma, cyst & - \\
\hline 7 & Fitzpatrick et al (1990) & 48 & $M$ & - & - & $2 \mathrm{mo}$ & - & Epidermal cyst & - \\
\hline 8 & Fitzpatrick et al (1990) & 39 & M & - & - & - & - & Subcutaneous nodule & - \\
\hline 9 & Argenyi et al (1991) & 67 & $M$ & $1.0 \times 1.0$ & Ear & $40 y$ & - & Lipoma, cyst & - \\
\hline 10 & Mehregan et al (1992) & 49 & $M$ & - & Ear & & - & Epidermoid cyst & - \\
\hline 11 & $\begin{array}{l}\text { Rodriguez-Fernandez } \\
\text { and Caro-Mancilla (1993) }\end{array}$ & 58 & $M$ & $3.0 \times 4.0$ & Elbow & $15 \mathrm{y}$ & - & Unknown & $\begin{array}{l}\text { With pleomorphic } \\
\text { changes }\end{array}$ \\
\hline 12 & Val-Bernal and Mira (1996) & 49 & $M$ & $2.5 \times 2.0$ & Ear & $5 y$ & - & Lipoma & - \\
\hline 13 & Lee et al (1996) & 32 & M & $1.2 \times 1.5$ & Ear & 5 y & & Lipoma, epidermal cyst & - \\
\hline 14 & Buyukbabani et al (1998) & 38 & $M$ & $2.5 \times 2.5$ & Ear & $10 y$ & + & Unknown & $\begin{array}{l}\text { Two previous } \\
\text { recurrences }\end{array}$ \\
\hline 15 & Buyukbabani et al (1998) & 36 & $M$ & $1.5 \times 1.5$ & Nose & $3 y$ & - & Unknown & - \\
\hline 16 & Obata et al (2001) & 54 & $\mathrm{~F}$ & - & Nose & $5 y$ & - & $\begin{array}{l}\text { Cavernous hemangioma, } \\
\text { liopoma }\end{array}$ & - \\
\hline 17 & Lin et al (2003) & 65 & $\mathrm{~F}$ & $2.0 \times 2.0$ & $\begin{array}{l}\text { Preauricular } \\
\quad \text { area }\end{array}$ & $10 y$ & - & Unknown & $\begin{array}{l}\text { Massive } \\
\text { bleeding on } \\
\text { excision }\end{array}$ \\
\hline 18 & Debloom et al (2006) & 50 & $\mathrm{~F}$ & $3.0 \times 2.5$ & Thigh & $5 \mathrm{y}$ & - & $\begin{array}{l}\text { Epidermoid cyst, } \\
\text { lipoma, leiomyoma }\end{array}$ & - \\
\hline 19 & Makino et al (2006) & 16 & $\mathrm{~F}$ & $2.5 \times 1.5$ & Buttock & - & - & Vascular tumor & $\begin{array}{l}\text { Ill-defined } \\
\text { margins, early } \\
\text { onset }\end{array}$ \\
\hline 20 & Jang et al (2006) & 57 & $M$ & $2.0 \times 1.5$ & Retroauricular & $4 \mathrm{y}$ & & Epidermal cyst & - \\
\hline 21 & Shin et al (this report) & 26 & $\mathrm{~F}$ & $1.0 \times 0.9$ & Ear helix & - & - & Mucoid cyst & - \\
\hline
\end{tabular}

reported herein are provided in Table 1. Cutaneous AMLs usually occur as solitary, asymptomatic, $1 \sim 4 \mathrm{~cm}$ nodules, commonly located in the acral skin or on the ear. The age of affected patients has ranged from 16 77 years (mean, 48.4 years), with a male-to-female ratio of $16: 5$. The most common clinical diagnoses were lipomas and epidermal cysts. Most of the lesions in the previous reports were described as "easily shelled-out", firm, and encapsulated nodules without a frank epidermal connection. Signs of TSC were absent in all the reported cases and recurrence has been noted in only one case after surgical resection. Histologically, all of the reported lesions demonstrated a well-circumscribed fibrous pseudocapsule containing mature adipose tissue, blood vessels, and surrounded by a thick muscular wall and smooth muscle cells intermixed with the surrounding muscle. These tumors do not generally display any degree of cellular atypia or mitoses, with the exception of one case ${ }^{6}$, thus lending strong credence to the benign classification. Rodriguez-Fernandez and Caro-Mancilla ${ }^{7}$ explained the marked pleomorphism without mitotic activity as a degenerative change or an ancient change of the tumor, excluding the possibility of malignant potential.

Although no recurrences have been observed in most of the cases, Buyukbabani et $\mathrm{al}^{10}$ experienced a patient with two previous local recurrences which seemed to be a result of incomplete surgical excision. These previous observations suggest that simple complete excision is generally adequate treatment for a cutaneous AML.

Cutaneous AMLs resemble the histologic features of renal AMLs; however, some differences exist in the clinical presentation and immunohistochemical staining. First, one-third of renal AMLs present with the clinical features of tuberous sclerosis, such as hypopigmented macules, shagreen patches, and angiofibromas, but none of the cutaneous AMLs have been shown to be associated with tuberous sclerosis. Second, HMB-45 was positive in $95 \%$ of the renal $\mathrm{AMLs}^{13}$, while none of the cutaneous AMLs were reactive. Third, unlike the renal form which shows a female predominance ${ }^{14}$, the cutaneous form shows a male predominance. According to these differences, cutaneous AMLs could be considered as a different disease entity to 
renal AMLs. Obata et $\mathrm{al}^{11}$ have proposed that AMLs might be caused by degeneration of the AML with replacement by fatty tissues based on being a long-standing lesion located at the acral sites, and therefore exposed to external forces. The similarity between AMLs and cutaneous AMLs with respect to male predominance, negative $\mathrm{HMB}-45$ immunohistochemical staining, rare multiplicity, and the presence of perivasclar epitheloid cells support this idea ${ }^{4}$. Therefore, some authors have recommended the term angioleiomyoma with fat to describe a cutaneous AML.

In conclusion, in contrast to renal AMLs, which are often invasive and may involve regional nodes that may recur, cutaneous AMLs are solitary, non-invasive, and not associated with tuberous sclerosis, and cured by simple surgical excision.

\section{REFERENCES}

1. Weiss SW, Goldblum JR, Enzinger FM. Enzinger and Weiss's soft tissue tumors. 4th ed. St. Louis: Mosby, 2001:605-607.

2. Argenyi ZB, Piette WW, Goeken JA. Cutaneous angiomyolipoma. A light-microscopic, immunohistochemical, and electron-microscopic study. Am J Dermatopathol 1991;13:497502.

3. Makino E, Yamada J, Tada J, Arata J, Iwatsuki K. Cutaneous angiolipoleiomyoma. J Am Acad Dermatol 2006;54:167171.

4. Beer TW. Cutaneous angiomyolipomas are HMB45 ne- gative, not associated with tuberous sclerosis, and should be considered as angioleiomyomas with fat. Am J Dermatopathol 2005;27:418-421.

5. Fitzpatrick JE, Mellette JR Jr, Hwang RJ, Golitz LE, Zaim MT, Clemons D. Cutaneous angiolipoleiomyoma. J Am Acad Dermatol 1990;23:1093-1098.

6. Mehregan DA, Mehregan DR, Mehregan AH. Angiomyolipoma. J Am Acad Dermatol 1992;27:331-333.

7. Rodriguez-Fernandez A, Caro-Mancilla A. Cutaneous angiomyolipoma with pleomorphic changes. J Am Acad Dermatol 1993;29:115-116

8. Tamura A, Ishikawa O, Miyachi Y. Subgaleal angiomyolipoma. J Dermatol 1994;21:514-517.

9. Val-Bernal JF, Mira C. Cutaneous angiomyolipoma. J Cutan Pathol 1996;23:364-368.

10. Buyukbabani N, Tetikkurt S, Ozturk AS. Cutaneous angiomyolipoma: report of two cases with emphasis on HMB-45 utility. J Eur Acad Dermatol Venereol 1998;11: 151-154.

11. Obata C, Murakami Y, Furue M, Kiryu H. Cutaneous angiomyolipoma. Dermatology 2001;203:268-270.

12. Debloom JR, Friedrichs A, Swick BL, Whitaker DC. Management of cutaneous angiomyolipoma and its association with tuberous sclerosis. J Dermatol 2006;33:783-786.

13. Roma AA, Magi-Galluzzi C, Zhou M. Differential expression of melanocytic markers in myoid, lipomatous, and vascular components of renal angiomyolipomas. Arch Pathol Lab Med 2007;131:122-125.

14. Blute ML, Malek RS, Segura JW. Angiomyolipoma: clinical metamorphosis and concepts for management. J Urol 1988; 139:20-24. 